\title{
VACANGIES IN HF-DOPED AND IN IRRADIATED ICE BY POSITRON ANNIHILATION TECHNIQUES
}

\author{
By M. Eldrup and O. E. Mogensen \\ (Chemistry Department, Risø National Laboratory, 40oo Roskilde, Denmark) \\ and J. H. Bilgram \\ (Laboratorium für Festkörperphysik, Eidg. Technische Hochschule Zürich, CH-8o49 \\ Zürich, Switzerland)
}

\begin{abstract}
Positron annihilation techniques, which are specifically sensitive to vacancy-type defects have been used to study the effect on ice of irradiation and HF doping. Main conclusions are that immobile water-molecule vacancies can be created at low temperatures by either irradiation or HF doping. Upon heating, the vacancies become mobile at about roo K. Some of them cluster into di- and multi-vacancies which grow in size with temperature up to at least $145 \mathrm{~K}$. A vacancy migration energy of $0.34 \pm 0.07 \mathrm{eV}$ is deduced, about three times higher than previously assumed. Possible mechanisms for vacancy formation by $\mathrm{HF}$ doping are discussed. Out-diffusion of $\mathrm{HF}$ is followed at $-26^{\circ} \mathrm{C}$ over several weeks. The diffusion constant derived agrees within uncertainty (a factor of two) with the large value obtained by Haltenorth and Klinger. In particular two results seem important for other parts of ice physics. One is that HF doping creates an appreciable increase in the vacancy concentration, the influence of which should be considered in models for other defects in ice. The other is that vacancies migrate at about 1 oo $\mathrm{K}$, a fact which might be important for the interpretation of some of the many "anomalous" effects observed in ice at about that temperature.
\end{abstract}

RÉsumé. Étude des lacunes dans la glace dopée avec HF et irradiée, par la technique d'annihilation de positon. Let techniques d'annihilation de positon, qui sont particulièrement adaptées aux défauts de type lacune, sons employées pour étudier l'effet de l'irradiation et du dopage avec HF sur la glace. Nos conclusions principales sont que le dopage avec HF et l'irradiation créent, à basse température, des lacunes non mobiles. Lors du chauffage, les lacunes deviennent mobiles au voisinage de roo K. Quelques unes d'entre elles forment des bi- ou multi-lacunes qui grossissent avec la température jusqu'à $145 \mathrm{~K}$ au moins. Nous obtenons une énergie de migration des lacunes de $0,34 \pm 0,07 \mathrm{eV}$, soit environ trois fois plus que la valeur précédemment admise. Des mécanismes de formation de lacunes par dopage avec HF sont discutés. La diffusion du HF hors du cristal est observée à $-26^{\circ} \mathrm{C}$ pendant plusieurs semaines. Le coefficient de diffusion obtenu est en accord (à un facteur deux près) avec la valeur élevée trouvée par Haltenorth et Klinger. En particulier, deux résultats semblent importants pour la physique de la glace. L'un est que le dopage avec HF crée un accroissement appréciable de la concentration de lacunes dont l'influence doit être considérée dans les modèles relatifs aux autres défauts dans la glace. L'autre point est que la migration des lacunes aux environs de ioo $\mathrm{K}$. est un fait qui peut être important dans l'interprétation de certains "effets anomaux" observés dans la giace au voisinage de cette température.

Zusammenfassung. Untersuchungen von Leerstellen in HF-dotiertem und in strahlungsgeschädigtem Eis mittels Positronzerstrahlungstechniken. Positronzerstrahlungstechniken, die besonders empfindlich sind auf leerstellenartige Fehlstellen, wurden dazu benützt, die Wirkung von Bestrahlung und HF-Dotierung auf Eis zu untersuchen. Die wesentlichen Schlussfolgerungen sind, dass unbewegliche Wassermolekülfehlstellen bei tiefen Temperaturen entweder durch Bestrahlung oder HF-Dotierung erzeugt werden können. Beim Aufheizen werden die Leerstellen bei ungefähr roo K beweglich. Einige von ihnen lagern sich in Doppel- und Mehrfachleerstellen zusammen, die mit der Temperatur bis mindestens $145 \mathrm{~K}$ in der Grösse wachsen. Es wird eine Leerstellenwanderungsenergie von $0,34 \pm 0,07 \mathrm{eV}$ abgeleitet, ein Wert ungefähr dreimal grösser als früher angenommen. Mögliche Mechanismen für die Leerstellenbildung durch HF-Dotierung werden besprochen. Ausdiffusion von $\mathrm{HF}$ wird bei $-26^{\circ} \mathrm{C}$ über mehrere Wochen verfolgt. Die daraus abgeleitete Diffusionskonstante stimmt innerhalb der Messungenauigkeit (Faktor zwei) mit dem hohen, von Haltenorth und Klinger gefundenen Wert überein. Für die anderen Bereiche der Eisphysik scheinen besonders zwei Ergebnisse wichtig: Zum einen, dass HF-Dotierung einen merklichen Anstieg in der Leerstellenkonzentration erzeugt, dessen Einfluss in Modellen für andere Fehlstellen in Eis beachtet werden sollte. Zum anderen, dass Leerstellen bei ungefähr ıoo K wandern, eine Tatsache, die wichtig sein kann für die Deutung einiger der vielen "anomalen" Effekte, die in Eis bei ungefähr dieser Temperatur beobachtet wurden.

\section{INTRODUCTION}

In another paper (Mogensen and Eldrup, I978) at this conference we discuss the positron annihilation techniques (PAT) and the results obtained by PAT on pure ice as a function of temperature. This was also to some extent discussed in a paper at the Ottawa Ice Conference (Mogensen and Eldrup, I973). A very important point is the fact that the positronium atom 
(Ps), which is a bound state of a positron and an electron, may become trapped in holes of less than average electronic density in the structure, i.e. in defects of vacancy type. By the trapping the measurable parameters (e.g. the lifetime and the Ps momentum distribution) change from those of Ps in the bulk. For example the ortho-Ps lifetime in the bulk is $0.7 \mathrm{~ns}$, but $\mathrm{I} .2 \mathrm{~ns}$ for ortho-Ps trapped in a vacancy in ice and still longer for ortho-Ps trapped in larger holes (vacancy clusters). Since Ps is sensitive only to vacancy-type defects and not to interstitials, and has a high sensitivity both with respect to concentration (for vacancies about $\mathrm{IO}^{-7}-\mathrm{IO}^{-4}$ mole fraction) and defect size (even single vacancies are detected), PAT is very well suited to obtain direct information about vacancies and larger clusters of vacancies.

In our other paper at this conference (Mogensen and Eldrup, I978) we describe results on thermally created vacancies, which give information on the vacancy formation energy. In the present paper we shall discuss PAT results which relate to the migration of vacancies. These results were obtained by creating vacancies at liquid-nitrogen temperature either by irradiation or by HF doping and then by following the annealing behaviour as a function of increasing temperature. The main results are that vacancies migrate at about $\mathrm{I}$ oo $\mathrm{K}$ and some of them cluster into small voids. From this behaviour we deduce a vacancy migration energy of $0.34 \pm 0.07 \mathrm{eV}$.

In this short conference contribution we will give a summary of the most important results from an ice physics point of view. A detailed account of the measurements has been or will be published elsewhere (Eldrup, I976; and papers in preparation by M. Eldrup, O. E. Mogensen, and J. H. Bilgram, and M. Eldrup, R. J. Douglas, and L. Lupton).

\section{EXPERIMENTAL}

The positron lifetime measurements were made with a conventional fast-slow coincidence system (West, I 973) with a resolution in terms of full width at half maximum (fwhm) $\approx 0.4$ ns. The positron source was 6-20 $\mu \mathrm{Ci}$ of ${ }^{22} \mathrm{NaCl}$ sealed between Mylar or nickel foils of thicknesses I $\mathrm{mg} / \mathrm{cm}^{2}$.

Angular correlation measurements on HF-doped ice were made with a standard linearslit angular-correlation set-up (West, 1973) at Risø. The angular resolution was fwhm $\approx 0.5$ milliradian $(\mathrm{mrad})$. About $20 \mathrm{mCi}$ of ${ }^{22} \mathrm{Na}$ was used as an external source. Other angularcorrelation measurements on irradiated pure ice (single crystals from S. J. Jones) were made at the larger angular correlation machine at Queen's University, Kingston, Ontario, Canada, with a resolution of $0.75 \mathrm{mrad}$ and using an external $25^{\circ} \mathrm{mCi}{ }^{58} \mathrm{Co}$ source.

\section{Irradiated ice}

Lifetime measurements were done on both poly- and monocrystalline samples. They were irradiated at $77 \mathrm{~K}$ in a ${ }^{60} \mathrm{Co}$ irradiation facility up to a dose of I I Megarad (Mrad). Measurements were carried out as function of dose and as function of temperature for doses of $4 . \mathrm{I}$ and I I Mrad.

Angular correlation measurements as function of temperature between 4 and $\mathrm{r} 6$ o $\mathrm{K}$ were done on a monocrystal which was irradiated by the positron source itself to an average dose of approximately 2 Mrad per day.

\section{HF-doped ice}

Monocrystals were grown by the Czochralski method doped to different HF concentrations (Bilgram, 1973). The concentrations were measured before and after measurements with an Orion specific-ion electrode on small pieces of the crystals which were melted. Samples were cut by lathe out of larger crystals, ground on emery paper, and polished with a silk cloth. Orientation of the crystals for the angular-correlation measurements was determined 
by polarized light and by etch pits or by X-ray diffraction. Handling of the crystals took place in a cold room at $-18^{\circ} \mathrm{C}$. Some $\mathrm{HF}$ certainly diffused out of the crystals during the handling period (one to a few hours). This gave rise to some uncertainty in the HF concentration of the crystals.

Both lifetime and angular-correlation measurements were made on the doped crystals. The parameters which were varied were (I) HF concentration, (2) measuring temperature, (3) cooling rate and the temperature from which cooling started, and (4) the time for which the sample was kept at a certain temperature, in other words the thermal history of the sample before a measurement.

\section{Data analysis}

The lifetimes and their relative intensities were extracted from the measured positron lifetime spectra by use of the computer programme for least-squares fitting Positronfit (Kirkegaard and Eldrup, I 974). Similarly the various components in the angular correlation curves were extracted by use of the least-squares fitting programme Paacfit (Kirkegaard and Mogensen, unpublished). A more detailed discussion of the data analysis is given by Mogensen and Eldrup (1977[b]) and Eldrup (1976).

\section{Results}

In pure ice below approximately $\mathrm{I}$ 70 K Ps is delocalized as evidenced by the narrow para-Ps side and central peaks in the angular-correlation curves (Mogensen and Eldrup, 1973, 1977[b], 1978). A main effect of both irradiation and HF doping is to create defects, which trap (i.e. localize) Ps. The trapping is observed in angular-correlation curves by the appearance of a "middle-broad" component (3-4 mrad) caused by localized para-Ps. In lifetime spectra the trapping is seen by the appearance of components with lifetime longer than the ortho-Ps lifetime in bulk ice $(0.7 \mathrm{~ns})$, in particular a $1.2 \mathrm{~ns}$ component. As discussed in, e.g. Mogensen and Eldrup (1978), there is good reason to believe that the defect responsible for most of the Ps trapping is the water-molecule vacancy. Thus, the "middle-broad" para-Ps component in angular correlation curves and the I.2 ns ortho-Ps lifetime component arise from Ps trapped in vacancies.

\section{Irradiated ice}

The main effect of $\gamma$-irradiation at $77 \mathrm{~K}$ in the lifetime spectra is the appearance of two long-lived components with lifetimes of $\tau_{3}=\mathrm{I} .2 \mathrm{~ns}$ and $\tau_{4}=2.3 \mathrm{~ns}$. They are associated with ortho-Ps trapped in vacancies and divacancies, respectively. Their intensities, $I_{3}$ and $I_{4}$, increase with dose showing an increase of the defect concentration. Simultaneously the intensity, $I_{1}$, of a short-lived component mainly associated with para-Ps decreases from about $22 \%$ to about $3 \%$ at I I Mrad. This is explained in part as a decrease in the Ps yield brought about by irradiation-created $\mathrm{OH}$ radicals (Eldrup, I976). The results of heating crystals irradiated with 4 . I and I I Mrad are shown in Figure I. The measuring time at each temperature was $3-4 \mathrm{~d}$. There is a clear transition at $93 \mathrm{~K}$. $I_{\mathrm{I}}$ increases sharply to its pre-irradiation value and $I_{3}$ and $I_{4}$ increase somewhat. $\tau_{3}$ is constrained to its average value $I_{2}$ ns at all temperatures (to reduce the scatter of the fitted parameters (Eldrup, I976)), but above approximately $105 \mathrm{~K}, \tau_{4}$ increases strongly. This shows that at these temperatures some orthoPs becomes trapped in larger holes (vacancy clusters) where ortho-Ps lives longer. Simultaneously, the intensities $I_{3}$ and $I_{4}$ drop.

Angular-correlation measurements on ice irradiated at $4 \mathrm{~K}$ showed a strong decrease of the intensities of the narrow para-Ps peaks and the appearance of a "middle-broad" (3-4 
mrad) component associated with para-Ps trapped in vacancies. On heating, the middlebroad component disappeared and the narrow component intensities increased strongly at about roo K (paper by M. Eldrup, R. J. Douglas, and L. Lupton, in preparation). This is evidence that the main annealing occurs at about $100 \mathrm{~K}$ and that vacancies created at lower temperatures disappear in this stage.

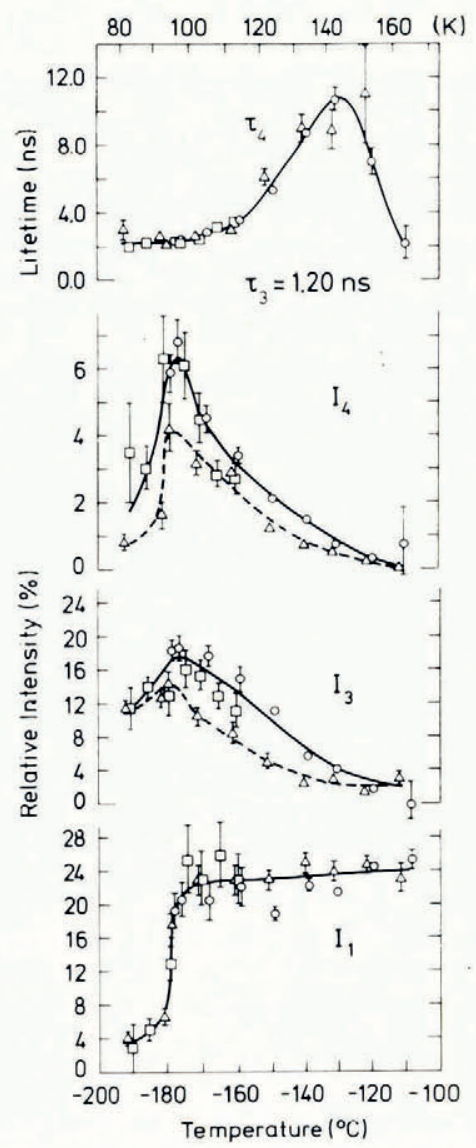

Fig. I. Lifetime results for pure ice $\gamma$-irradiated at $77 K$ and measured as a function of increasing temperature. Circles are for polycrystalline samples (I I Mrad). Triangles are for one set of monocrystals (4.I Mrad). Squares are for another set of monocrystals (II Mrad). The full and the dashed curves for $I_{3}$ and $I_{4}$ are drawn for the $I I$ and 4.1 Mrad points, respectively. The changes at $93 K$ are associated with vacancy migration, the increase of $\tau_{4}$ with the growth of the size of voids.

\section{HF-doped ice}

As briefly mentioned above, doping of ice with HF gives rise to the appearance of a I.2 ns component in lifetime spectra and an angular correlation component $3-4 \mathrm{mrad}$ broad. The intensities of these components increase with increasing HF concentration. Mogensen and Eldrup (1 973 ) showed $I_{3}$ (the intensity of the $\tau_{3}=1.2 \mathrm{~ns}$ component) as a function of HF concentration for polycrystalline ice (frozen aqueous solutions). The results for dopcd monocrystals follow the same curves, but the scatter of the points is much larger than for polycrystals. Probably, this is partly due to the uncertainty in HF concentration (because of out-diffusion during sample handling) and partly due to uncertainty in cooling rate (see 
below). Mogensen and Eldrup (1973) also showed angular correlation curves illustrating the effect of HF doping.

The measurements carried out on crystals doped to 25 p.p.m. HF were particularly detailed. First the samples were quenched from $-18^{\circ} \mathrm{C}$ to liquid-nitrogen temperature (cooled in less than I min), and measurements were then made as a function of increasing temperature. The measuring time at each temperature was about $3 \mathrm{~d}$. In Figure 2 the most important lifetime parameters for two different sets of samples are shown $\left(\tau_{3}\right.$ was constrained to $\mathrm{I} .20 \mathrm{~ns})$. At low temperatures $I_{3} \approx 54 \%$, i.e. all ortho-Ps becomes trapped in vacancies.
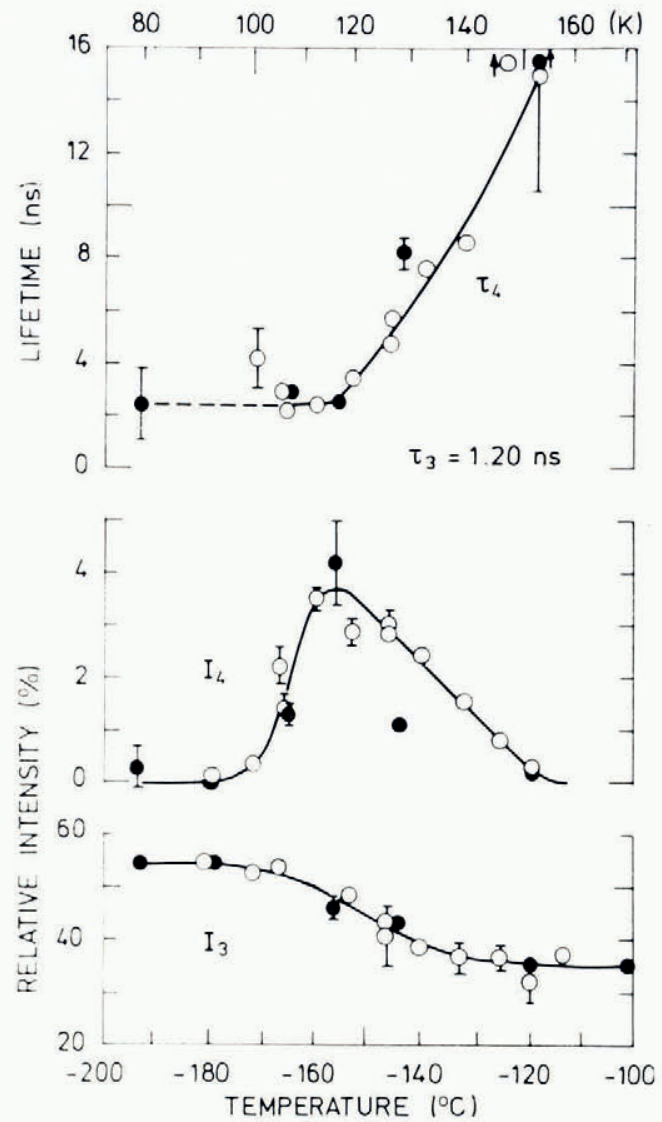

Fig. 2. Annealing of 25 p.p.m. $\mathrm{HF}$-doped crystals after quenching from $-20^{\circ} \mathrm{C}$ to liquid-nitrogen temperature. Lifetimes and intensities of the two long-lived components (trapped ortho-Ps) are shown. Open and closed circles are for two different sets of samples. The increase of $I_{4}$ is associated with migration of vacancies which form divacancies, the increase of $\tau_{4}$ with the growth of the size of voids.

At about $\mathrm{I}$ oo $\mathrm{K}$ the intensity $I_{4}$ of a longer-lived component $\left(\tau_{4} \approx 2.5 \mathrm{~ns}\right)$ starts to increase. Its lifetime stays constant up to about $115 \mathrm{~K}$ above which it increases strongly, while the intensity drops to zero at $\mathrm{I} 60 \mathrm{~K}$. This increase of $\tau_{4}$ is very similar to that observed for $\gamma$-irradiated ice (Fig. I) and the appearance of such a long-lived component shows again that some ortho-Ps becomes trapped in clusters of vacancies at these temperatures.

After the above-mentioned annealing up to $\mathrm{i} 6 \mathrm{o} \mathrm{K}$, one set of samples was cooled slowly from $160 \mathrm{~K}$. Measurements were made as a function of decreasing temperature (Fig. 3, open circles). Each measurement took $3-4 \mathrm{~d}$ and the cooling rate in between was $\mathrm{I} \mathrm{deg} / \mathrm{min}$. 
Later on the sample was cooled to $95 \mathrm{~K}$ from $\mathrm{I} 73 \mathrm{~K}$ with a rate of $\mathrm{I} \mathrm{deg} / \mathrm{min}$ (squares) and as fast as possible (triangles). Figure 3 shows that the lifetime $\tau_{3}$ is essentially constant at I. 2 ns, but its intensity $I_{3}$ (and hence the concentration of vacancies) measured at low temperature is very dependent on cooling rate. This observation also holds true for other HF concentrations, for which quenching from temperatures above $170 \mathrm{~K}$ results in a larger $I_{3}$ at low temperature than does cooling by I deg/min.

Finally, the set of samples was heated to $-26^{\circ} \mathrm{C}$ and measurements were made as a function of time. The intensity $I_{3}$ of the $\tau_{3}=\mathrm{I} .2 \mathrm{~ns}$ component is shown in Figure 4. Within a week the intensity has dropped to that in pure ice (the hatched area indicates $I_{3}$ (I.2 ns) for pure ice), but stays slightly below this value for the rest of the measuring period. The sample was melted afterwards and a concentration of about I p.p.m. HF was found. Similar results were obtained by measuring a 4 p.p.m. HF sample as function of temperature, viz. that at temperatures above $c .220 \mathrm{~K} I_{3}$ fell below the pure ice values, and the measured HF concentration after several days at higher temperatures was about o.6 p.p.m. HF.
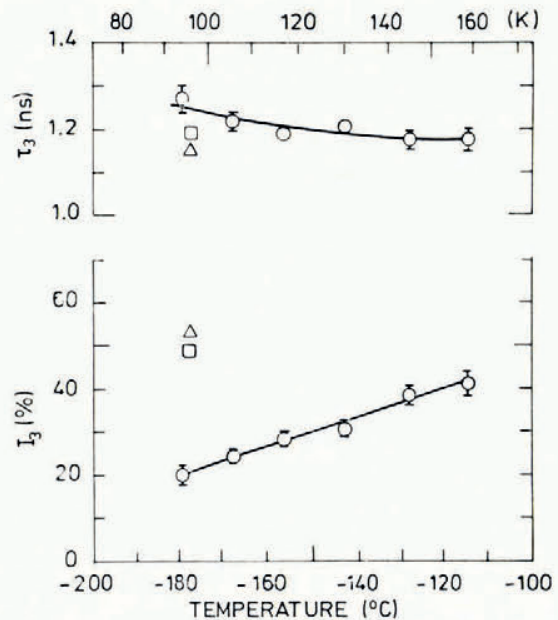

Fig. 3. Effect of cooling rate from about $170 \mathrm{~K}$ of a 25 p.p.m. HF-doped crystal. The "I.2 ns" lifetime and its intensity are shown. Cooling rates are: Circles, $I$ deg/min between points, $3-4 d$ measuring time at each point; average cooling rate = $2 \times \mathrm{IO}^{-3} \mathrm{deg} / \mathrm{min}$. Squares, I deg/min. Triangles, quenched, i.e. about $100 \mathrm{deg} / \mathrm{min}$.

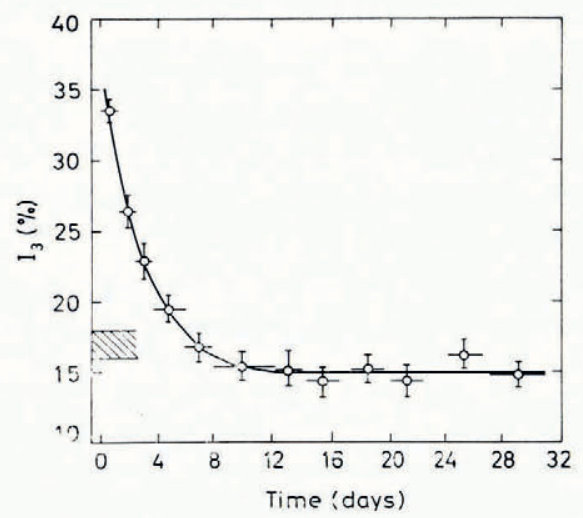

Fig. 4. The intensity $I_{3}$ of the "I.2 ns" component in ice initially doped to 25 p.p.m. HF as function of time, measured at $-{ }_{2} 6^{\circ} \mathrm{C}$. The hatched area indicates results for pure ice. The decrease of $I_{3}$ is associated with out-diffusion of $H F$. 


\section{Discussion}

In our other paper at the conference (Mogensen and Eldrup, 1978) we discuss the evidence that the 1.2 ns lifetime component and the middle-broad (3-4 mrad) angular correlation component arise from Ps trapped in vacancies, in other words that our measurements give direct information about vacancies. We shall therefore base our discussion of our present results on this conclusion.

\section{Vacancy migration}

First let us discuss the changes in parameters taking place around roo $\mathrm{K}$ in both irradiated and highly HF-doped crystals (Figs I and 2).

In the field of radiation chemistry, a number of investigations of irradiated ice have been carried out, in particular to study trapped electrons and $\mathrm{OH}$ and $\mathrm{H}$ radicals which are created during the irradiation. Irradiation at liquid-nitrogen temperature creates $\mathrm{H}$ and $\mathrm{OH}$ radicals, most likely by dissociation of water molecules by which $\mathrm{H}$ and $\mathrm{OH}$ are ejected into the crystal lattice leaving a vacancy behind. The interstitial $\mathrm{OH}$ radicals (identified by an absorption at $2800 \AA$ ) are stable at liquid-nitrogen temperature but about $120 \mathrm{~K}$ (for a heating rate of a few degrees per minute) these radicals disappear (Ghormley and Hochanadel, I971; Kawabata, 1976). The yield of trapped electrons (absorption at $6200 \AA$ ) peaks at I $20 \mathrm{~K}$ and decreases strongly at higher temperatures. Kawabata (1976) suggests that the electrons are trapped in radiation-created vacancies which anneal out around $120 \mathrm{~K}$. This interpretation agrees very well with the picture obtained from the results of Figure $\mathrm{I}$.

The decrease of the intensities $I_{\mathrm{I}}$ and the narrow angular-correlation para-Ps peaks $I_{\mathrm{N}}$ with increasing dose is interpreted as a result of $\mathrm{OH}$-radical formation. The presence of this radical with a high electron affinity is likely to decrease the Ps formation probability (Mogensen, 1974) which is seen as a reduction of $I_{1}$ and $I_{N}$. With the slow heating rates used in PAT measurements the $\mathrm{OH}$ radicals disappear at about $100 \mathrm{~K}$ causing the Ps yield, and hence $I_{1}$ and $I_{\mathrm{N}}$, to go up. Also $I_{3}$ and $I_{4}$ increase showing that more Ps is now trapped in vacancies and divacancies (since more Ps is formed). However, the increase of $I_{3}$ is rather small, indicating a decrease of the vacancy concentration simultaneously with the disappearance of the interstitial $\mathrm{OH}$ radicals. These concentration changes can be brought about by the migration of either the radicals or the vacancies (or maybe both). In either case vacancies will trap the $\mathrm{OH}$ radicals into substitutional positions and the vacancy (and interstitial $\mathrm{OH}$ ) concentration will thus decrease in agreement with observations. We find there is convincing evidence to believe that at least the vacancies migrate at about $\mathrm{r}$ oo $\mathrm{K}$. The increase of $\tau_{4}$ (Figs I and 2) above approximately i io K shows that holes larger than mono- and divacancies (i.e. vacancy clusters) are formed. This requires the migration of mono- and/or multivacancies in this temperature region. Migration of vacancies much below roo K seems unlikely, as an appreciable non-equilibrium vacancy concentration is present at $100 \mathrm{~K}$. The angular correlation measurements also support this. The strongest evidence for vacancy migration, however, is the appearance of the $2.5 \mathrm{~ns}$ component $\left(\tau_{4}, I_{4}\right)$ above $100 \mathrm{~K}$ in $\mathrm{HF}$-doped ice (cf. the increase of $I_{4}$ from o to $4 \%$ in Figure 2). It shows that divacancies (or maybe trivacancies) are formed at this temperature. There seems to be no other way for this to happen than by migration and pairing of vacancies. $\tau_{4}$ does not start to increase until IO-I 5 deg higher, suggesting that divacancies become mobile (or unstable) and cluster at and above this temperature into multivacancies.

Thus we can conclude from the above discussion, supported by the results of Kawabata (1976) that an appreciable migration of vacancies in ice take place over a time period of days at about $100 \mathrm{~K}$. If the time scale is minutes the temperature has to be raised to about $120 \mathrm{~K}$ to give significant migration. 
From the vacancy migration temperature it is possible to calculate the activation energy for migration. Experimentally we observe the temperature at which the concentration of vacancies (a supersaturation of which has been frozen-in at low temperature) decreases or at which divacancies are formed. This happens when vacancies migrate and reach sinks such as interstitials, other vacancies, and dislocations. In order to reach a sink a vacancy must, on the average, jump a certain number of times determined by the sink concentration. The jump frequency increases with increasing temperature as determined by the activation energy for vacancy migration. Hence, at a certain temperature the jump frequency will be large enough for vacancies to reach sinks within the time spent at that temperature (i.e. the measuring time), and a change in vacancy concentration or a divacancy signal will be measured. The migration energy can therefore be deduced from the migration temperature and the estimated sink concentration as follows (Eldrup, r976).

The average number of jumps $n$ of a vacancy during a time $t$ is

$$
n=t \nu,
$$

where $v$ is the average jump frequency. It is given by (Shewmon, r 963 ):

$$
\nu=\nu_{0} \exp \left(S_{\mathrm{m}} / k\right) \exp \left(-E_{\mathrm{m}} / k T\right),
$$

where $v_{0}$ is a frequency close to lattice vibration frequencies, $k$ is the Boltzmann constant, $T$ the absolute temperature, $S_{\mathrm{m}}$ the entropy change, and $E_{\mathrm{m}}$ the activation energy for vacancy migration. Ramseier ( 1967 ) finds that an expression by Zener for the total entropy change of diffusion is in good agreement with experients. Therefore we will use Zener's expression for $S_{\mathrm{m}}$ :

$$
S_{\mathrm{m}} \approx \beta\left(E_{\mathrm{m}} / T_{\mathrm{mp}}\right),
$$

where $\beta$ is a constant (o.33 according to Ramseier ( 1967$)$ ) and $\mathcal{T}_{\mathrm{mp}}$ is the ice melting temperature. By inserting the expressions for $\nu$ and $S_{\mathrm{m}}$ (Equations (I) and (3)) into Equation (2) we get

$$
E_{\mathrm{m}}=\frac{k T}{\mathrm{I}-\beta T / T_{\mathrm{mp}}} \ln \frac{\nu_{0} t}{n} .
$$

$E_{\mathrm{m}}$ is given by the temperature $T$ at which a vacancy on the average jumps $n$ times during the time $t$. For vacancies of a concentration of about ro p.p.m. to cluster, they have to jump $n \approx \mathrm{IO}^{4-10^{5}}$ times during the typical measuring time of $t=2 \times 1 \mathrm{O}^{5} \mathrm{~s}$. This clustering sets in at a temperature of about $T=9^{8 \mathrm{~K}}$. With these numbers and $v_{0}=4.7 \times 10^{12} \mathrm{~s}^{-1}$ (Ramseier, r 967 ) we obtain $E_{\mathrm{m}}=0.3 \mathrm{eV}$. If the concentration of sinks for vacancies is taken I oo times higher (i.e. $n$ Ioo times smaller) $E_{\mathrm{m}}$ will increase by $0.04 \mathrm{eV}$. Other uncertainties are of course present in this simplified determination of $E_{\mathrm{m}}$, probably amounting to a total of about $\pm 20 \%$. Hence, the activation energy for vacancy migration is estimated at $E_{\mathrm{m}}=$ $0.34 \pm 0.07 \mathrm{eV}$. The activation energy for self-diffusion, which is generally accepted to take place by a vacancy mechanism, is well determined at $Q=0.62 \mathrm{eV}$ (Ramseier, I967). Since $Q=E_{\mathrm{m}}+E_{\mathrm{f}}$, where $E_{\mathrm{f}}$ is the vacancy formation energy, we get $E_{\mathrm{f}}=0.28 \pm 0.07 \mathrm{eV}$ in agreement with the estimates from pure ice (Mogensen and Eldrup, 1977[b], 1978). These new experimentally determined values for $E_{\mathrm{m}}$ and $E_{\mathrm{f}}$ are strikingly different from older estimates by Gränicher (1958) and Fletcher (1970) of $E_{\mathrm{f}} \approx 0.5 \mathrm{eV}$. A very important effect of this is that the equilibrium vacancy concentration close to $0^{\circ} \mathrm{C}$ is at least $\mathrm{IO}^{4}$ times higher than previously assumed (Mogensen and Eldrup, I977[a], 1978).

\section{Void formation}

In both irradiated and HF-doped ice the vacancy migration is followed at higher temperatures by a strong increase of $\tau_{4}$ and a simultaneous decrease of its intensity $I_{4}$ (Figs $\mathrm{I}$ and 2). As mentioned earlier, the long lifetimes of several nanoseconds can only be explained as the 
lifetimes of ortho-Ps trapped in holes in the lattice, i.e. vacancy clusters or voids. The size of these voids (indicated by $\tau_{4}$ ) increases with temperature, at least up to $145 \mathrm{~K}$. A rough estimate of their size suggests that a ro ns lifetime is equivalent to a ${ }_{5} \AA$ A diameter (Eldrup, I976). The growth of small voids into larger ones probably takes place by a net emission of vacancies from the smaller voids and a net absorption of vacancies by larger voids (Mae, I968) analogous to the way by which void coarsening takes place in metals. During the void coarsening some vacancies are lost to other vacancy sinks, and the total void concentration decreases. Both effects contribute to the decrease of the intensity $I_{4}$ of the void component.

Cavities in ice, much larger than the voids observed here, have been seen by optical and electron microscopes (Mae, I968; Unwin and Muguruma, 1972), under, however, quite different experimental conditions. The advantage of PAT measurements clearly is that it is possible to follow the formation and growth of the voids from the starting mono- (and in some cases di-) vacancy configuration. This has so far not been possible by other experimental methods.

\section{Vacancy creation by $\mathrm{HF}$ doping}

An important problem, of course, concerns the mechanism by which doping with $\mathrm{HF}$ creates vacancies in ice in excess of the pure-ice thermal-equilibrium concentration. Two fundamentally different possibilities should be considered. First, that the vacancies observed at low temperatures are created during cooling down of the crystal as a result of the stress in the crystal induced by thermal gradients. Secondly, that HF influences the equilibrium properties of vacancies at a given temperature, such as the vacancy concentration and jump frequency, with the effect that the equilibrium concentration increases and it becomes easier to quench-in a high concentration at low temperatures.

Let us first consider the first possibility. Jones and Gilra (1973) have shown that doping with $\mathrm{HF}$ strongly increases the dislocation density. The thermal gradients in the samples in our case are probably much larger than in their crystals. Therefore, we would expect the dislocation densities in our samples to be appreciably larger than those observed by Jones and Gilra, whether the role of HF is to ease or provoke dislocation formation (Jones and Gilra, 1973). One would expect that the creation and movement of dislocations would be accompanied by formation of some vacancies. Fast cooling to low temperature would then produce larger stresses and higher dislocation and hence vacancy concentrations for a given $\mathrm{HF}$ concentration than slow cooling would, in agreement with observations (Fig. 3). Since vacancies are mobile above about $100 \mathrm{~K}$ they will be in thermal equilibrium above this temperature. To explain the high $I_{3}$ values at $-100^{\circ} \mathrm{C}$ (Figs 2 and 3 ) and at $-26^{\circ} \mathrm{C}$ (Fig. 4) we would therefore have to assume that Ps can be trapped by dislocations, where ortho-Ps would have a lifetime close to its lifetime in vacancies. Against this interpretation is the fact that in pure ice no trapping has been observed at low temperature after quenching from

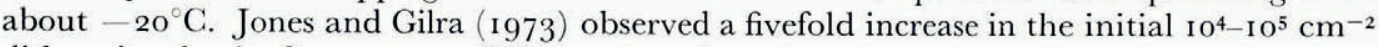
dislocation density for a 5 p.p.m. HF concentration. To account for the amount of Ps trapping at this HF concentration (Mogensen and Eldrup, 1973) a concentration of trapping sites equivalent to about I p.p.m. of vacancies is probably required. If each molecular position along a dislocation line is assumed to be a trapping site equivalent to a vacancy, a dislocation density of about $10^{9} \mathrm{~cm}^{-2}$ is needed. The concentration of vacancies created during the formation of the dislocations would probably be much less than I p.p.m. Hence, to account for the void formation a dislocation density of $\mathrm{IO}^{10}-\mathrm{IO}^{11} \mathrm{~cm}^{-2}$ would probably be necessary. It seems unlikely that such high densities could be obtained even by the combined action of the present quenching and HF doping (Muguruma and Higashi, 1963).

Let us consider the second possibility, viz. that doping with $\mathrm{HF}$ increases the equilibrium vacancy concentration and makes it possible to quench-in at least part of the high concentration present at higher temperatures. Bilgram and others (I976) have previously discussed the 
creation of vacancies by Frenkel-pair formation as a result of $\mathrm{HF}$ doping to interpret NMR spin-lattice relaxation data. We shall discuss another possibility here. It seems very probable that there will be a certain binding energy between vacancies and one or more other defects in the ice lattice (e.g. F, ionic, or Bjerrum defects). In that case, the total concentration of vacancies will consist of the free vacancies in the bulk plus vacancies bound to defects. If for instance there is an attraction between vacancies and substitutional $\mathrm{F}$, and/or $\mathrm{L}$, and/or $\mathrm{H}_{3} \mathrm{O}^{+}$defects (or bound states of these) one would expect that HF doping would increase the total vacancy concentration. The maximum increase would be about the same order of magnitude as the HF concentration. Vacancies present at low temperatures will (at least partly) be quenched-in vacancies. A larger cooling rate is expected to result in a larger quenched-in concentration of vacancies. This is in qualitative agreement with observations (Fig. 3). Very slow cooling ( $\approx 2 \times \mathrm{IO}^{-3} \mathrm{deg} / \mathrm{min}$ ) results in a relatively low vacancy concentration at $95 \mathrm{~K}$, giving rise to $I_{3}=20 \%$; a cooling rate of $\mathrm{I} \mathrm{deg} / \mathrm{min}$ results in a higher concentration $\left(I_{3}=49 \%\right.$ ), while quenching gives $I_{3}=54 \%$. (Thus, quenching gives a higher $I_{3}$ $(54 \%)$ at $95 \mathrm{~K}$ than the one observed at $\mathrm{r} 6 \mathrm{o} \mathrm{K}(4 \mathrm{r} \%$, Fig. 3), although the quenched-in concentration of vacancies at $95 \mathrm{~K}$ cannot be higher than the concentration at $\mathrm{r} 6 \mathrm{o} \mathrm{K}$. This difference in $I_{3}$ is associated with a decrease of the Ps trapping rate per vacancy with increasing temperature (paper by M. Eldrup, O. E. Mogensen, and J. H. Bilgram, in preparation) and will not be discussed further here.) With a higher equilibrium vacancy concentration than in pure ice, it is of course easier to quench-in a certain vacancy concentration at low temperatures. But the results illustrated in Figure 3, viz. that even a rather slow cooling rate (I deg/ $\min$ ) is sufficient to quench-in an appreciable vacancy concentration, show that the equilibrium vacancy concentration at these temperatures is attained rather slowly. Only for very low cooling rates (circles in Fig. 3) do we see a clear decrease of the vacancy concentration with decreasing temperature, maybe approaching an equilibrium situation. If a binding exists between the vacancies and other defects it is reasonable to expect that this will reduce the vacancy mobility. Also the mobility of vacancies not bound to other defects might be influenced by the presence of defects. Actually, the migration of vacancies in 25 p.p.m. HF-doped ice as evidenced by the increase of $I_{4}$ (Fig. 2) seems to take place IO-I 5 deg above the migration in pure, irradiated ice (Fig. I). Hence, it is not unreasonable to expect that vacancies in thermal equilibrium at higher temperatures can be quenched-in at lower temperatures in HF-doped ice.

We have discussed two fundamentally different mechanisms which might explain the increase in vacancy concentration observed in HF-doped ice. It seems that the more plausible is the latter mechanism by which the vacancy equilibrium properties are influenced by the doping, resulting in an increased equilibrium vacancy concentration by vacancy-defect binding, and resulting in a decrease of the average vacancy jump frequency, making it easier to quench-in vacancies at low temperature.

Our earlier, less detailed, measurements on ice doped with other impurities than HF showed that in all cases trapping of Ps (probably in vacancies) took place as a result of doping (Milošević-Kvajić and others, I972; Eldrup and others, 1972). Thus, the increase in vacancy concentration at low temperatures seems to be a general effect of doping. The reason that HF apparently gives the largest effect may be its larger solubility. However, we shall not go into further details here. To obtain a more quantitative understanding of the mechanisms of vacancy formation and migration in ice doped with HF (and other impurities), more experimental as well as theoretical work is needed, the latter taking into account the interaction of vacancies with other defects.

\section{Diffusion of $\mathrm{HF}$}

The decrease of $I_{3}$ with time for an initially 25 p.p.m. HF doped crystal at $-26^{\circ} \mathrm{C}$ (Fig. 4) (and also for an initial 4 p.p.m. HF doping) is ascribed to out-diffusion of HF, as evidenced 
also by the decrease of the HF concentration to the I p.p.m. level found in the crystal after the measurements. Using a simple trapping model which relates $I_{3}$ to the vacancy concentration (West, 1973), and assuming HF and vacancy concentrations to be proportional, we find that during the first week HF diffuses with a diffusion constant that is in agreement with the results of Haltenorth and Klinger ( 1969 ) within the uncertainty of about a factor of two. For longer times than a week, $I_{3}$ falls below the pure-ice value. This might be a result of a decrease in trapping rate per vacancy due to the presence of $\mathrm{HF}$, or it might be that trapping in vacancies bound to other defects gives a slightly shorter ortho-Ps lifetime than trapping in free vacancies in pure ice, which will lead to the same experimental result.

The HF concentration of I p.p.m. measured after $30 \mathrm{~d}$ is much larger than expected from the diffusion constant given by Haltenorth and Klinger (r 969 ). This could be because an equilibrium has been established between the $\mathrm{HF}$ in the crystal and the out-diffused gaseous HF surrounding the sample in the sample container.

Another explanation could be the one proposed by Bilgram and others (1976) which postulates a fast interstitial diffusion at high HF concentrations and a slow substitutional diffusion at low HF concentrations. Haltenorth and Klinger (1969, 1977) have proposed that the fast HF diffusion might be along dislocations or small-angle grain boundaries.

\section{Effects at Ioo $K$}

A number of different effects have been observed to take place in ice at temperatures close to $100 \mathrm{~K}$ such as in electrical polarization and depolarization (Dengel and others, i 964 ; Sixou and Jeneveau, 1973), in fluorescence and thermoluminescence (Grossweiner and Matheson, I954) in heat capacity (Pick, 1969; Matsuo and others, I973), in elastic constants (Helmreich, 1969), in yield of trapped excess electrons (Kawabata, 1976), and in annealing of damage created by protons in channelling experiments (Golecki and others, i 976; Golecki and Jaccard, 1978). With the results of the present PAT investigations on ice in mind, it seems worthwhile to consider the possible role of vacancy migration for the explanation of these effects. Only Kawabata (I976) seems to have done so, as mentioned earlier.

\section{Conclusion}

In the present conference contribution we have discussed results obtained by positron annihilation techniques (PAT) on irradiated and on HF-doped ice. These techniques are specifically sensitive to vacancy-type defects. Experimental information on vacancies and vacancy clusters can therefore be obtained. The main conclusions of the work are the following: Water-molecule vacancies can be created at low temperature by either irradiation or $\mathrm{HF}$ doping. Upon heating the vacancies become mobile at about roo K. From this migration temperature a vacancy migration energy of $0.34 \pm 0.07 \mathrm{eV}$ is deduced; this is two or three times higher than earlier estimates (Unwin and Muguruma, I972; Bilgram and others, I976), but in agreement with our estimates of the vacancy formation energy. Some of the migrating vacancies cluster to form di- and multivacancies that grow in size with increasing temperature, at least up to $145 \mathrm{~K}$. Possible mechanisms by which HF doping may create vacancies are discussed. We suggest that the presence of $\mathrm{HF}$ increases the equilibrium vacancy concentration by binding of vacancies to other defects. Out-diffusion of $\mathrm{HF}$ is observed and the diffusion constant (at least for high HF concentrations) found to agree with previous results (Haltenorth and Klinger, r 969 ) to within a factor of two.

To get a better understanding of the vacancy formation by HF doping more experiments are needed, as well as theoretical models taking into account the interaction of vacancies with other defects. There seems still to be a lack of detailed understanding of the effects of and behaviour of $\mathrm{HF}$ in ice. Also the possible role of vacancy migration for the many "anomalous" effects observed at temperatures close to roo $\mathrm{K}$ deserves theoretical consideration. 


\section{Acknowledgements}

We wish to thank S. J. Jones for providing ice single crystals, and N. J. Pedersen for valuable technical assistance.

\section{REFERENCES}

Bilgram, J. H. 1973. Perfect highly doped ice crystals by the Czochralski method. (In Whalley, E., and others, ed. Physics and chemistry of ice: papers presented at the Symposium on the Physics and Chemistry of Ice, held in Ottawa, Canada, 14-18 August 1972. Edited by E. Whalley, S. 7. Jones, L. W. Gold. Ottawa, Royal Society of Canada, p. 246-50.)

Bilgram, J. H., and others. 1976 . Spin-lattice relaxation in $\mathrm{HF}$ and $\mathrm{NH}_{3}$ doped ice and the outdiffusion of impurities, [by] J. H. Bilgram, J. Roos and H. Gränicher. Zeitschrift für Physik, B, Vol. 23, No. I, p. I-9.

Dengel, O., and others. 1964. Ferroelectric behaviour of ice, [by] O. Dengel, U. Eckener, H. Plitz and N. Riehl. Physics Letters, Vol. 9, No. 4, p. 291-92.

Eldrup, M. 1976. Vacancy migration and void formation in $\gamma$-irradiated ice. Journal of Chemical Physics, Vol. 64, No. 12, p. $5283-90$.

Eldrup, M., and others. 1972. Positron lifetimes in pure and doped ice and in water, [by] M. Eldrup and O. E. Mogensen and G. Trumpy. Zournal of Chemical Physics, Vol. 57, No. I, p. 495-504.

Fletcher, N. H. 1970. The chemical physics of ice. Cambridge, University Press. (Cambridge Monographs on Physics.)

Ghormley, J. A., and Hochanadel, C. J. 197I. Production of $\mathrm{H}, \mathrm{OH}$, and $\mathrm{H}_{2} \mathrm{O}_{2}$ in the flash photolysis of ice. Journal of Physical Chemistry, Vol. 75, No. 1, p. 40-44.

Golecki, I., and Jaccard, C. 1978. Radiation damage in ice at low temperatures studied by proton channelling. Journal of Glaciology, Vol. 21 , No. 85 , p. $247-58$

Golecki, I., and others. I976. Étude des dégats de radiation dans la glace à basse température par la canalisation de protons, par I. Golecki, F. Rudolf et C. Jaccard. Helvetica Physica Acta, Vol. 49, Fasc. 5, p. 70 I-02.

Gränicher, H. I958. Gitterfehlordnung und physikalische Eigenschaften hexagonaler und kubischer Eiskristalle. Zeitschrift für Kristallographie, Vol. I 10, p. 432-71.

Grossweiner, L. I., and Matheson, M. S. 1954. Fluorescence and thermoluminescence of ice. Journal of Chemical Physics, Vol. 22, No. 9, p. 1514-26.

Haltenorth, H., and Klinger, J. 1969 . Diffusion of hydrogen fluoride in ice. (In Riehl, N., and others, ed. Physics of ice: proceedings of the international symposium on physics of ice, Munich, Germany, September 9-14, 1968. Edited by $\mathcal{N}$. Riehl, B. Bullemer, H. Engelhardt. New York, Plenum Press, p. 579-84.)

Haltenorth, H., and Klinger, J. 1977. Solubility of hydrofluoric acid in ice $I_{h}$ single crystals. Solid State Communications, Vol. 21, No. 6, p. 533-35.

Helmreich, D. 1969. Elastic anomalies of ice at low temperatures. (In Riehl, N., and others, ed. Physics of ice: proceedings of the international symposium on physics of ice, Munich, Germany, September 9-14, I968. Edited by $\mathcal{N}$. Riehl, B. Bullemer, H. Engelhardt. New York, Plenum Press, p. 231-38.)

Jones, S. J., and Gilra, N. K. I 973 . X-ray topographical study of dislocations in pure and HF-doped ice. Philosophical Magazine, Eighth Ser., Vol. 27, No. 2, p. 457-72.

Kawabata, K. 1976. Electron traps in irradiated crystalline ice. Journal of Chemical Physics, Vol. 65, No. 6, p. $2235-42$.

Kirkegaard, P., and Eldrup, M. 1974. Positronfit extended: a new version of a program for analysing positron lifetime spectra. Computer Physics Communications, Vol. 7, No. 7, p. 40 I-09.

Kirkegaard, P., and Mogensen, O. E. Unpublished. PAACFIT: a program for analysing positron annihilation angular correlation spectra. [[Risø National Laboratory, Roskilde, Denmark. Report] M-1615, 1973.]

Mae, S. 1968. Void formation during non-basal glide in ice single crystals under tension. Philosophical Magazine, Eighth Ser., Vol. 18, No. 151, p. 101-14.

Matsuo, T., and others. I 973 . Relaxational proton ordering in two-dimensional and three-dimensional ices, [by] T. Matsuo, M. Oguni, O. Haida, H. Suga and S. Seki. (In Whalley, E., and others, ed. Physics and chemistry of ice: papers presented at the Symposium on the Physics and Chemistry of Ice, held in Ottawa, Canada, I4-18 August 1972. Edited by E. Whalley, S. 7. Jones, L. W. Gold. Ottawa, Royal Society of Canada, p. 272-77.)

Milošević-Kvajić, M., and others. I972. Angular correlation of annihilation photons in frozen aqueous solutions, [by] M. Milošević-Kvajić, O. E. Mogensen, G. Kvajić and M. Eldrup. Fournal of Chemical Physics, Vol. 56, No. 6 , p. $2567-71$.

Mogensen, O. E. 1974. Spur reaction model of positronium formation. Journal of Chemical Physics, Vol. 6o, No. 3 , p. 998-1004.

Mogensen, O. E., and Eldrup, M. 1973. Positronium interaction with defects and impurities in ice. (In Whalley, E., and others, ed. Physics and chemistry of ice: papers presented at the Symposium on the Physics and Chemistry of Ice, held in Ottawa, Canada, I4-18 August 1972. Edited by E. Whalley, S. F. Fones, L. W. Gold. Ottawa, Royal Society of Canada, p. $165-69$.)

Mogensen, O. E., and Eldrup, M. I977[a]. On the vacancy concentration in ice. Physics Letters, Vol. 6oA, No. 4, p. $325^{-26}$.

Mogensen, O. E., and Eldrup, M. 1977[b]. Positronium Bloch function, and trapping of positronium in vacancies, in ice. Risø Report (Risø National Laboratory, Roskilde, Denmark) No. 366.

Mogensen, O. E., and Eldrup, M. 1978. Vacancies in pure ice studied by positron annihilation techniques. Journal of Glaciology, Vol. 2 I, No. 85, p. 85-99. 
Muguruma, J., and Higashi, A. I963. Observation of etch channels on the (ooor) plane of ice crystal produced by nonbasal glide. Journal of the Physical Society of Japan, Vol. 18, No. 9, p. 1261-69.

Pick, M. A. 1969 . The specific heat of ice Ih. (In Riehl, N., and others, ed. Physics of ice: proceedings of the international symposium on physics of ice, Munich, Germany, September 9-14, 1968. Edited by $\mathcal{N}$. Riehl, B. Bullemer, $H$. Engelhardt. New York, Plenum Press, p. 344-47.)

Ramseier, R. O. I 967 . Self-diffusion of tritium in natural and synthetic ice monocrystals. Fournal of Applied Physics, Vol. 38, No. 6, p. $2553^{-56}$.

Shewmon, P. W. 1963 . Diffusion in solids. New York, McGraw-Hill.

Sixou, P., and Jeneveau, A. r973. Electric polarization and depolarization effects in pure and doped ice at low temperature: dipolar relaxation and ferroelectricity. (In Whalley, E., and others, ed. Physics and chemistry of ice : papers presented at the Symposium on the Physics and Chemistry of Ice, held in Ottawa, Canada, I4-I8 August 1972. Edited by E. Whalley, S. F. Jones, L. W. Gold. Ottawa, Royal Society of Canada, p. 295-302.)

Unwin, P. N. T., and Muguruma, J. 1972. Electron microscope observations on the defect structure of ice. Physica Status Solidi, A, Vol. 14, p. 207-16.

West, R. N. 1973. Positron studies of condensed matter. Advances in Physics, Vol. 22, No. 3, p. $263-383$.

\section{DISGUSSION}

R. W. Whitworth: For HF-doped ice you have shown results on the annealing of quenched crystals. Is there evidence from your experiments for the presence of vacancies in the doped ice before quenching? What happens if the annealing of the voids is followed to higher temperatures?

M. Eldorup: At $-26^{\circ} \mathrm{C}$ we have studied the out-diffusion of $\mathrm{HF}$ in a crystal originally doped to 25 p.p.m. HF (see Fig. 4). Initially the intensity of a 1.2 ns component is much higher than in pure ice, giving evidence for a strongly increased vacancy concentration before quenching. We have only followed the annealing up to about $-\mathrm{IOO}^{\circ} \mathrm{C}$, since the void concentration at this temperature is below the detection limit $\left(I_{4} \approx 0 \%\right)$. At higher temperatures the outdiffusion of $\mathrm{HF}$ also becomes an experimental problem. 